\title{
Incidence and Risk Factors of Pneumonitis in Patients with Non-Small Cell Lung Cancer: An Observational Analysis of Real-World Data
}

\author{
Jerzy E. Tyczynski (D) Ravi Potluri · Ryan Kilpatrick • Debasish Mazumder • \\ Anirban Ghosh · Alexander Liede
}

Received: February 22, 2021 / Accepted: March 30, 2021 / Published online: April 28, 2021

(C) The Author(s) 2021

\section{ABSTRACT}

Introduction: The incidence of pneumonitis, a treatment-related adverse event (AE) in nonsmall cell lung cancer (NSCLC) patients, has been studied in the United States mostly through clinical trials and retrospective chart reviews. Few analyses of real-world data have been published. This study of a large nationally representative health records database estimated the incidence and predictors of pneumonitis among treated NSCLC patients between 2008 and 2018.

Methods: The Optum $^{\circledR}$ electronic health records (EHR) database includes data on over 80 million patients from more than 50 healthcare plans. The cohort of primary NSCLC patients was identified using ICD-9/10 codes. Natural language processing of unstructured data from physicians' notes facilitated extraction of biomarker (epidermal growth factor receptor [EGFR] and programmed death ligand-1 [PD-

J. E. Tyczynski $(\bowtie) \cdot$ R. Kilpatrick · A. Liede

AbbVie Inc, North Chicago, IL, USA

e-mail: jerzy.tyczynski@abbvie.com

R. Potluri

SmartAnalyst Inc, New York, NY, USA

A. Liede

AbbVie Limited, Dublin, Ireland

D. Mazumder · A. Ghosh

SmartAnalyst India Pvt. Ltd, Gurugram, India
L1]) status. Cumulative incidence was estimated as the proportion with pneumonitis overall, by clinical characteristics, and line of therapy (LOT) after diagnosis and treatment. Univariate analysis of incidence rates (cases/1000 personyears) enabled the identification of significant predictors of risk. Competing risk regression identified predictors of pneumonitis.

Results: The cohort included 81,628 patients. Overall, $19.0 \%$ developed pneumonitis during any LOT, with a cumulative incidence of $33.7 \%$ and $17.0 \%$ for patients with a prior history of pneumonitis and those without, respectively. Univariate analyses revealed several factors associated with pneumonitis $(p<0.05)$. While factors varied between LOTs, common factors included male gender, squamous histology, history of diabetes or pneumonitis, EGFR-negative status, monotherapy immunomodulatory drugs, or history of radiation therapy. Multivariable competing risk regression showed that male gender, history of pneumonitis, EGFRnegative status, use of other targeted therapies, use of immunomodulatory drugs, and history of radiation therapy predicted pneumonitis.

Conclusion: Pneumonitis is significantly associated with NSCLC treatment. Knowledge of its predictors identified in this study may help devise strategies to mitigate its impact, enhancing treatment adherence and improving outcomes. 


\section{PLAIN LANGUAGE SUMMARY}

Pneumonitis is a side effect of non-small cell lung cancer (NSCLC) treatment. Real-world data on its incidence in the United States is not extensive. In this study, the Optum ${ }^{\circledR}$ electronic health records database with data on over 80 million patients from more than 50 healthcare plans across the United States was used to estimate the incidence and predictors of pneumonitis in NSCLC patients treated between 2008 and 2018. A total of 81,628 NSCLC patients were identified using disease-specific codes. Physicians' notes in their health records were subjected to natural language processing to identify presence of epidermal growth factor receptor (EGFR) and programmed death ligand1 (PD-L1) receptors in tumors. Proportions of patients with pneumonitis overall, by clinical characteristics, and line of therapy (LOT) were calculated. Univariate analysis of incidence (cases per 1000 person-years) a multivariable competing risk regression helped identify risk predictors. Overall, $19.0 \%$ of patients developed pneumonitis during any LOT. Incidence was $33.7 \%$ and $17.0 \%$ in patients with and without prior pneumonitis, respectively. Univariate analysis revealed factors associated with pneumonitis, including male gender, squamous histology, history of diabetes or pneumonitis, EGFR-negative status, monotherapy immunomodulatory drugs, or history of radiation therapy. Multivariable competing risks regression analysis showed that male gender, history of pneumonitis, EGFR-negative status, use of other targeted therapies, use of immunomodulatory drugs, and history of radiation therapy were significantly associated with pneumonitis. Pneumonitis is significantly associated with NSCLC treatment. Knowledge of its predictors may help design interventions to lessen its impact, promoting compliance with treatment and improving outcomes.

Keywords: Incidence; Non-small cell lung cancer; NSCLC; Pneumonitis; Predictors; Realworld data

\section{Key Summary Points}

Why carry out this study?

Lung cancer ranks highest in mortality of all cancers in the United States.

Pneumonitis is a potentially serious side effect of non-small-cell lung cancer (NSCLC) treatment that may lead to treatment discontinuation.

The objective was to estimate the cumulative incidence and incidence rates, and identify predictors of treatmentrelated pneumonitis in NSCLC patients.

What was learned from the study?

Nineteen percent of patients developed pneumonitis over the course of their NSCLC treatment, with male gender, history of pneumonitis, use of other targeted therapies, use of immunomodulatory drugs, and history of radiation therapy all predicting pneumonitis.

Awareness of the pneumonitis predictors identified in this study may help clinicians devise strategies to mitigate the impact of pneumonitis, enhance treatment adherence, and improve outcomes.

\section{DIGITAL FEATURES}

This article is published with digital features, including a summary slide and plain language summary, to facilitate understanding of the article. To view digital features for this article, go to https://doi.org/10.6084/m9.figshare. 14333708 . 


\section{INTRODUCTION}

Cancer of the lung ranks second among all cancer types in the United States in terms of incidence and first in terms of attributable deaths, with estimates indicating that this cancer type will account for 235,760 new cases and 131,880 deaths in 2021 [1]. An estimated $57 \%$ of patients with lung cancer have metastases at diagnosis, with a 5-year relative survival rate in such patients of only $5 \%$ [2]. A majority (85\%) of all lung cancer cases are of the non-small cell lung cancer (NSCLC) histologic group, with squamous cell carcinoma and adenocarcinoma being the predominant histologic subtypes of NSCLC [3].

Treatment of NSCLC has evolved significantly in recent years. The approval of targeted therapies including third-generation tyrosine kinase inhibitors (TKIs) and immune checkpoint inhibitors (ICIs) has led to improved longterm survival, relegating conventional chemotherapy to a secondary role $[4,5]$. However, these targeted therapies are associated with a potentially fatal treatment-induced adverse event (AE), pneumonitis, which has been documented in patients treated with programmed death 1 (PD-1)/programmed death ligand 1 (PD-L1) ICIs [6-9], epidermal growth factor receptor-tyrosine kinase inhibitors (EGFR-TKIs) [10-12], and anaplastic lymphoma kinase (ALK) inhibitors [13]. Symptoms typically associated with pneumonitis resulting from the use of targeted NSCLC therapies include cough, dyspnea, fever, chest pain, and hypoxia, accompanied by pulmonary infiltrates that are evident in chest computer tomography (CT) images [14, 15]. Although patients usually respond to oral corticosteroids, some may develop significant dyspnea requiring the use of supplemental oxygen, discontinuation of NSCLC therapy, or intravenous corticosteroids and additional immunosuppressive agents (e.g., infliximab, cyclophosphamide, or mycophenolate mofetil) [14-16]. While rare, high-grade (grade 3/4) pneumonitis is associated with significant morbidity and mortality in a small proportion (1\%) of those affected [14, 15, 17]. Guidelines issued by the American Society of
Clinical Oncology (ASCO) recommend permanent discontinuation of NSCLC therapy in patients with severe pneumonitis (grades 3 and 4) [18], leading to cessation of potentially beneficial treatment.

To date, studies using real-world data on NSCLC patients have focused on subgroups of interest such as those receiving a PD-L1 inhibitor [19-21], patients with stage III NSCLC [22], or, more recently, efforts evaluating the reliability of real-world endpoints [23-25]. We designed a study to examine an important safety concern among individuals diagnosed with NSCLC, which may compromise a patient's ability to complete the prescribed treatment. Here, we estimate the cumulative incidence and incidence rates, and identify predictors of treatment-related pneumonitis in NSCLC patients across all disease stages who had received currently approved therapies from a large and representative real-world data set in the United States.

\section{METHODS}

\section{Data Source}

The data analyzed were obtained from the Optum $^{\circledR}$ electronic health records (EHR) database [26]. This database contains records from approximately 140,000 physicians at over 700 hospitals, and 7000 clinics across more than 80 integrated delivery networks (IDNs) in the United States [27]. De-identified information on demographic and socioeconomic categories, coded diagnoses and procedures, prescribed medications, laboratory results, and clinical administrative data is available for $>80$ million patients from diverse settings (inpatient, outpatient, and ambulatory) across all census regions in the United States [27]. The information does not include any identifiable information as defined by the Health Insurance Portability and Accountability Act (HIPAA) of 1996 [28], eliminating the need for institutional review board (IRB) approval or waiver [29].

Optum's ${ }^{\circledR}$ proprietary natural language processing (NLP)-based data are used to identify concepts that may not be captured by 
International Classification of Diseases (ICD) or procedure codes, and complements conventional data elements captured in EHR data relating to diagnosis, drugs, procedures, laboratory test results, and patient characteristics. The NLP concepts are identified and created based on broad topics such as Medications, Signs, Disease and Symptoms (SDS), Measurements, and Observations, and are harvested from the notes fields within the electronic medical records. The data used for development of each NLP concept is de-identified and accuracy is verified through a series of quality assurance steps prior to release for use. Each NLP concept included in the data is associated with a unique subject record and a date of observation, allowing longitudinal tracking of concepts such as "non-small cell lung cancer" or "pneumonitis" over time.

\section{Cohort Assembly}

The study cohort was identified using $\geq 1$ primary lung cancer diagnosis code (ICD-9-CM: 162, ICD-10-CM: C33, C34), and no mention of small cell lung cancer (SCLC) in SDS data, $\geq 1$ mention of NSCLC in SDS data or core NSCLC drug use, first active date $\geq 12$ months prior to index lung cancer diagnosis date ("index date"), index date after January 1, 2008, no lung surgery or other cancer diagnosis during the 12 -month period prior to the index date, and age $\geq 18$ years on the index date. Core NSCLC drugs considered for the inclusion criteria were platinum- and non-platinum-based chemotherapies, ICIs (alone or in combination), EGFR-TKIs, and other targeted therapies (Table 1).

\section{Lines of Treatment}

Lines of therapy (LOT) for each patient were established using business rules centered on (1) identifying continuous periods of drug use, (2) establishing concurrent use of individual drugs and concatenating such drugs into a treatment regimen, and (3) earmarking periods of use of distinct regimens as LOTs. The drugs considered for this analysis are listed in Table 1 and

Table 1 Components of the lines of treatment and definitions of treatment categories for the competing risks regression analyses

Treatment categories for construction of LOTs

\begin{tabular}{|c|c|}
\hline Drug class & Therapeutic agents \\
\hline $\begin{array}{l}\text { Platinum-based } \\
\text { chemotherapy }\end{array}$ & Carboplatin and cisplatin \\
\hline $\begin{array}{l}\text { Non-platinum-based } \\
\text { chemotherapy }\end{array}$ & $\begin{array}{l}\text { Docetaxel, gemcitabine, nab- } \\
\text { paclitaxel, paclitaxel, } \\
\text { pemetrexed, or vinorelbine }\end{array}$ \\
\hline $\begin{array}{l}\text { ICI (alone or in } \\
\text { combination) }\end{array}$ & $\begin{array}{l}\text { Nivolumab, pembrolizumab, } \\
\text { atezolizumab, or durvalumab }\end{array}$ \\
\hline TKI & $\begin{array}{l}\text { Afatinib, erlotinib, gefitinib, } \\
\text { osimertinib, alectinib, brigatinib, } \\
\text { cabozantinib, ceritinib, } \\
\text { crizotinib, nintedanib, or } \\
\text { vandetanib }\end{array}$ \\
\hline $\begin{array}{l}\text { Other targeted } \\
\text { therapies }\end{array}$ & $\begin{array}{l}\text { Bevacizumab, dabrafenib, } \\
\text { necitumumab, ramucirumab, } \\
\text { trametinib, or ado-trastuzumab }\end{array}$ \\
\hline
\end{tabular}

Treatment categories for the competing risks regression analyses

Category

Definition of category

Any ICI monotherapy

Regimen contains only one drug from among nivolumab, pembrolizumab, atezolizumab, or durvalumab
Any ICI combination therapy

EGFR-TKI therapy
Regimen contains at least two drugs, with nivolumab, pembrolizumab, atezolizumab, or durvalumab being one of the drugs in the regimen

Regimen contains at least one EGFR-TKI, and afatinib, erlotinib, gefitinib, osimertinib, alectinib, brigatinib, cabozantinib, ceritinib, crizotinib, nintedanib, or vandetanib is one of the drugs in the regimen 
Table 1 continued

\begin{tabular}{ll}
\hline Treatment categories for construction of LOTs \\
\hline $\begin{array}{l}\text { Other targeted } \\
\text { therapy }\end{array}$ & $\begin{array}{c}\text { Regimen contains at least one } \\
\text { drug, and bevacizumab, } \\
\text { dabrafenib, necitumumab, } \\
\text { ramucirumab, trametinib, or } \\
\text { ado-trastuzumab is one of the } \\
\text { drugs in the regimen }\end{array}$ \\
Rlatinum-based & $\begin{array}{l}\text { Regimen contains at least one } \\
\text { drug, and carboplatin or } \\
\text { chemotherapy }\end{array}$ \\
the regimen \\
Ron-platinum-based in one of the drugs in \\
Regimen contains at least one \\
drug, and docetaxel, \\
gemcitabine, nab-paclitaxel, \\
paclitaxel, pemetrexed, or \\
vinorelbine is one of the drugs in \\
the regimen
\end{tabular}

$\overline{E G F R}$ epidermal growth factor receptor; ICI immune checkpoint inhibitor; LOT line of therapy; NSCLC nonsmall cell lung cancer; $S C L C$ small cell lung cancer; $S D S$ signs, diseases, and symptoms; TKI tyrosine kinase inhibitor

comprise both chemotherapies and targeted agents (including EGFR-TKIs and ICIs).

\section{Analyses Performed}

Pneumonitis occurrences were identified using ICD-9 codes (495.0-495.9, 506.0, 507.0, 507.1, 507.8, 508.0, 508.8, 516.32, 516.33, 516.35, 518.3, and 997.39), ICD-10 codes (J67.0-J68.0, J69.0, J69.1, J69.8, J70.0, J70.2, J82, J84.113, J84.114, J84.2, J95.4), and SDS terms ("allergic interstitial pneumonitis," "chemical pneumonitis," "cryptogenic organizing pneumonitis," "desquamative interstitial pneumonitis," "interstitial pneumonitis," "organizing pneumonitis," "pneumonitis," "radiation pneumonitis"). These data were then used to perform the analyses described below.

\section{Cumulative Incidence}

The cumulative incidence of pneumonitis was defined as the percentage of patients with a diagnosis of pneumonitis during (1) the entire follow-up period and (2) in each respective LOT period. Cumulative incidence estimates were stratified by the presence/absence of a history of pneumonitis prior to the start of the evaluation period, LOT, and biomarker subgroup (EGFRpositive/negative and PD-L1-positive/negative). A patient was deemed to be an EGFR mutant if identified as EGFR-positive from the SDS data set or had received osimertinib, erlotinib, afatinib, gefitinib, or dacomitinib (monotherapy or in combination with chemotherapy drugs) in LOT1.

\section{Incidence Rates and Relative Risk}

Incidence rates, expressed as cases per 1000 person-days, were calculated as the number of patients diagnosed with at least one occurrence of pneumonitis between the start and end of follow-up for each of the two respective evaluation periods, divided by the sum of the duration from the start of the evaluation period to the first occurrence of pneumonitis for those patients with at least one diagnosis of pneumonitis in the evaluation period and the sum of the duration from the start to the end of the evaluation period (or end of follow-up) for patients without a pneumonitis event in the evaluation period. The entire follow-up period was defined as the time from index date to the end of follow-up. Each LOT evaluation period was defined as the start of a LOT to 30 days after the end of that LOT or one day prior to the start of the next LOT, whichever was earlier, or (where there was no next LOT) up to the end of follow-up for or the end of the last LOT plus 30 days, whichever was earlier. These incidence rates were used to carry out a univariate analysis of 16 covariates (Table 4) to determine the relative risk (RR) of each covariate. The RR was calculated as IR1/IR2, where IR1 is the incidence rate for patients having the condition reported in terms of incidents/1000 person-days and IR2 is the incidence rate for patients who do not 


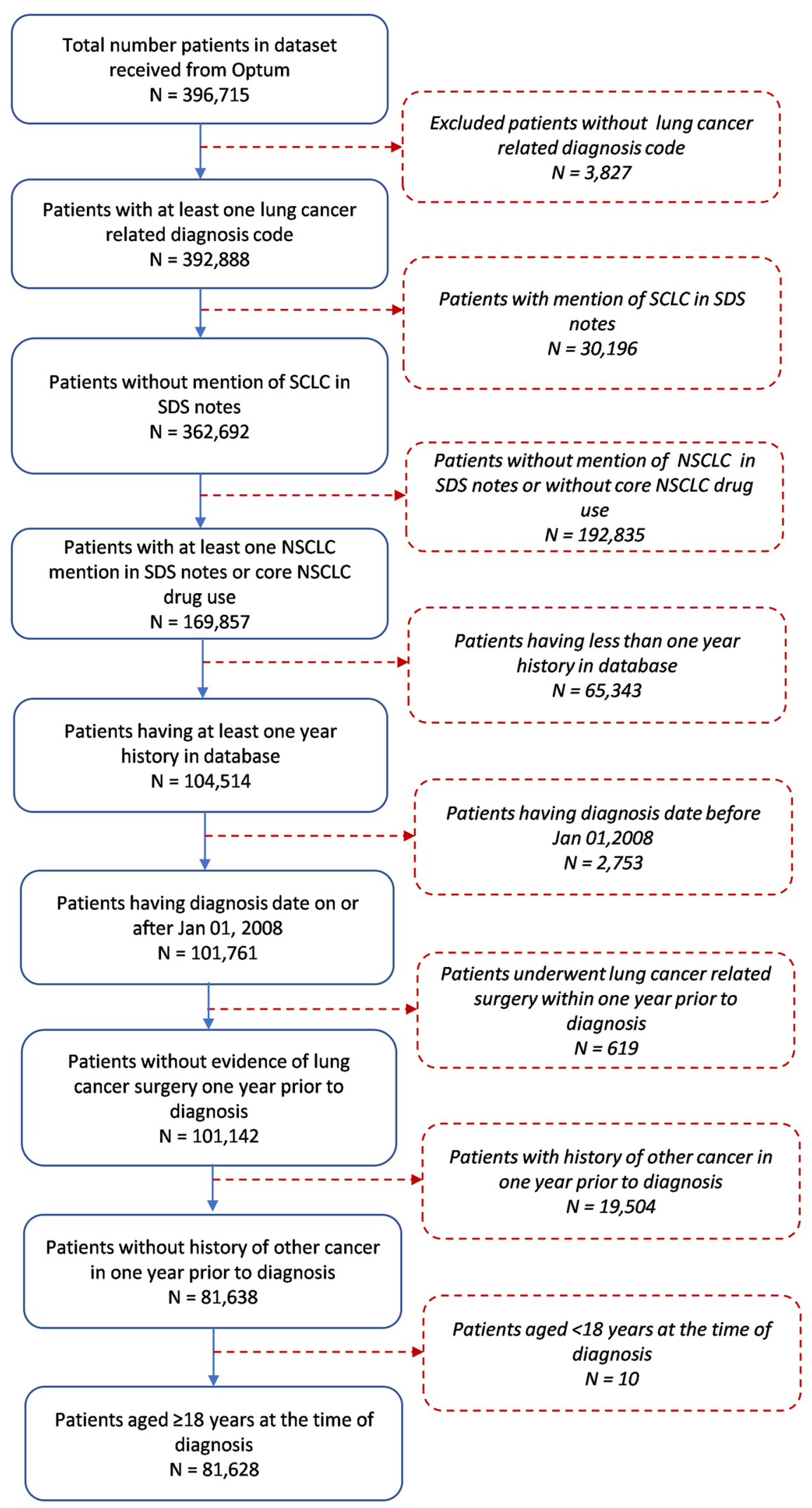


4 Fig. 1 Selection of the analysis cohort. NSCLC, non-small cell lung cancer; SCLC, small cell lung cancer; SDS, signs, diseases, and symptoms

have the condition reported as incidents/1000 person-days. $P$ values to test the relative risk of developing pneumonitis were derived from a generalized linear model after accounting for differential patient follow-up times. Patients with unknown histology were excluded from this analysis. The covariates included demographic characteristics, histology, biomarker status, prior history of comorbidities/adverse events, and treatment groups. There were six treatment groups defined: any ICI monotherapy, any ICI combination therapy, EGFR-TKI therapy, other targeted therapy, platinum-based chemotherapy, any non-platinum-based chemotherapy (Table 1 ).

\section{Competing Risk Regression}

A multivariable competing risk regression (30) was used in order to account for the competing risk of death prior to the development of pneumonitis. We used 16 covariates (Table 5) used to identify significant predictors of pneumonitis. The significance level was 0.05 .

\section{RESULTS}

\section{Selection of the Study Cohort}

The study cohort included a total of 81,628 patients identified as depicted in Fig. 1. Almost half $(49 \%)$ of the cohort were male, $46.9 \%$ resided in the Midwest followed by $28.4 \%$ in the South, and $85 \%$ were Caucasian (Table 2). The mean age of patients at diagnosis was 69 years $(\mathrm{SD}=10.1)$, and patients with Eastern Cooperative Oncology Group (ECOG) score $\geq 2$ constituted $30 \%$ of patients with a valid score. Sixty percent of patients had localized disease, while $38.3 \%$ were EGFR-positive. The mean Charlson Comorbidity Index $(\mathrm{CCI})$ was $1.8(\mathrm{SD}=2.56)$.

\section{Drug-Treated Patients}

A total of $21.7 \%$ of patients were treated with medications for $\geq 1$ LOT and had a median follow-up (MFU) of 401 days from their index diagnosis, with $8.8 \%$ having $\geq 2$ LOTs (MFU: 566 days) and $3.8 \%$ having $\geq 3$ LOTs (MFU: 742) (Table 3).

\section{Pneumonitis Cumulative Incidence}

Overall, $19.0 \%$ (95\% confidence intervals [CI]: $18.5-19.6 \%$ ) of treated patients developed pneumonitis during any LOT, while $26.2 \%$ (95\% CI: $24.3-28.1 \%$ ) of those with a prior history of pneumonitis in any time prior to LOT 1 and $17.0 \%$ (95\% CI: $16.4-17.6 \%$ ) of those without a previous history of pneumonitis developed the condition during any LOT. Regardless of biomarker subgroup, histologic category, or LOT, in general, a higher proportion of patients with a prior history of pneumonitis developed the condition than patients without a prior history (Fig. 2). Except for PD$\mathrm{L} 1+$ non-squamous cell carcinoma patients, an increase in the cumulative incidence of pneumonitis in each subsequent LOT was observed across EGFR and PD-L1 status, by squamous/ non-squamous histology. Overall, there was an increase in cases of pneumonitis of $2.7 \%$ from LOT 1 to LOT 3 (data not shown). Between the various subgroups, the largest increase between LOTs 1 and 3 was seen for PD-L1 - patients with a non-squamous histology, with cumulative incidence going up from $13.6 \%$ to $22.7 \%$. The smallest increase was seen in EGFR+/nonsquamous patients (9.7-12.1\%). PD-L1+/nonsquamous patients was the only exception to this pattern going from $17.9 \%$ in LOT 1 to $13.8 \%$ in LOT3.

Of the 16 variables that were evaluated as risk factors for the development of pneumonitis in univariate analysis, several were shown to be significantly $(P<0.05)$ associated with a higher risk for developing the condition in at least two LOTs (Table 4). Some common factors included: male gender, squamous histology, EGFR-negative status, history of pneumonitis, history of diabetes, monotherapy treatment with an 
Table 2 Demographic and clinical characteristics of the analytical cohort by histology

\begin{tabular}{|c|c|c|c|c|c|c|c|c|}
\hline \multirow[t]{3}{*}{ Baseline characteristics } & \multicolumn{8}{|c|}{ Histology } \\
\hline & \multicolumn{2}{|l|}{ Overall } & \multicolumn{2}{|c|}{ Non-squamous ${ }^{a}$} & \multicolumn{2}{|c|}{ Squamous } & \multicolumn{2}{|c|}{ Not otherwise specified } \\
\hline & $\begin{array}{l}n \\
81,628\end{array}$ & $\begin{array}{l}\%^{b} \\
100 \%\end{array}$ & $\begin{array}{l}n \\
46,670\end{array}$ & $\begin{array}{l}\%^{\mathbf{b}} \\
57 \%\end{array}$ & $\begin{array}{l}n \\
21,540\end{array}$ & $\begin{array}{l}\%^{b} \\
26 \%\end{array}$ & $\begin{array}{l}n \\
13,418\end{array}$ & $\begin{array}{l}\%^{b} \\
16 \%\end{array}$ \\
\hline \multicolumn{9}{|l|}{ Year of diagnosis } \\
\hline 2008 & 2535 & $3.1 \%$ & 1125 & $2.4 \%$ & 613 & $2.8 \%$ & 797 & $5.9 \%$ \\
\hline 2009 & 3781 & $4.6 \%$ & 1809 & $3.9 \%$ & 998 & $4.6 \%$ & 974 & $7.3 \%$ \\
\hline 2010 & 5186 & $6.4 \%$ & 2566 & $5.5 \%$ & 1362 & $6.3 \%$ & 1258 & $9.4 \%$ \\
\hline 2011 & 6575 & $8.1 \%$ & 3455 & $7.4 \%$ & 1533 & $7.1 \%$ & 1587 & $11.8 \%$ \\
\hline 2012 & 8037 & $9.8 \%$ & 4334 & $9.3 \%$ & 1966 & $9.1 \%$ & 1737 & $12.9 \%$ \\
\hline 2013 & 9423 & $11.5 \%$ & 5275 & $11.3 \%$ & 2483 & $11.5 \%$ & 1665 & $12.4 \%$ \\
\hline 2014 & 10254 & $12.6 \%$ & 5909 & $12.7 \%$ & 2674 & $12.4 \%$ & 1671 & $12.5 \%$ \\
\hline 2015 & 10077 & $12.3 \%$ & 6072 & $13.0 \%$ & 2740 & $12.7 \%$ & 1265 & $9.4 \%$ \\
\hline 2016 & 9870 & $12.1 \%$ & 6097 & $13.1 \%$ & 2696 & $12.5 \%$ & 1077 & $8.0 \%$ \\
\hline 2017 & 8948 & $11.0 \%$ & 5590 & $12.0 \%$ & 2523 & $11.7 \%$ & 835 & $6.2 \%$ \\
\hline 2018 & 6942 & $8.5 \%$ & 4438 & $9.5 \%$ & 1952 & $9.1 \%$ & 552 & $4.1 \%$ \\
\hline \multicolumn{9}{|l|}{ Gender } \\
\hline Male & 39987 & $49.0 \%$ & 20762 & $44.5 \%$ & 12722 & $59.1 \%$ & 6503 & $48.5 \%$ \\
\hline Female & 41599 & $51.0 \%$ & 25885 & $55.5 \%$ & 8809 & $40.9 \%$ & 6905 & $51.5 \%$ \\
\hline Unknown & 42 & $0.1 \%$ & 23 & $0.0 \%$ & 9 & $0.0 \%$ & 10 & $0.1 \%$ \\
\hline \multicolumn{9}{|l|}{ Region } \\
\hline Midwest & 38317 & $46.9 \%$ & 21450 & $46.0 \%$ & 10708 & $49.7 \%$ & 6159 & $45.9 \%$ \\
\hline South & 23171 & $28.4 \%$ & 13070 & $28.0 \%$ & 6445 & $29.9 \%$ & 3656 & $27.2 \%$ \\
\hline West & 7559 & $9.3 \%$ & 4671 & $10.0 \%$ & 1828 & $8.5 \%$ & 1060 & $7.9 \%$ \\
\hline Northeast & 10380 & $12.7 \%$ & 6263 & $13.4 \%$ & 1974 & $9.2 \%$ & 2143 & $16.0 \%$ \\
\hline Other/Unknown & 2201 & $2.7 \%$ & 1216 & $2.6 \%$ & 585 & $2.7 \%$ & 400 & $3.0 \%$ \\
\hline \multicolumn{9}{|l|}{ Race } \\
\hline Caucasian & 69138 & $84.7 \%$ & 38996 & $83.6 \%$ & 18659 & $86.6 \%$ & 11483 & $85.6 \%$ \\
\hline African American & 7270 & $8.9 \%$ & 4385 & $9.4 \%$ & 1795 & $8.3 \%$ & 1090 & $8.1 \%$ \\
\hline Asian & 1164 & $1.4 \%$ & 869 & $1.9 \%$ & 137 & $0.6 \%$ & 158 & $1.2 \%$ \\
\hline Other/unknown & 4056 & $5.0 \%$ & 2420 & $5.2 \%$ & 949 & $4.4 \%$ & 687 & $5.1 \%$ \\
\hline \multicolumn{9}{|l|}{ Ethnicity } \\
\hline Non-Hispanic & 73931 & $90.6 \%$ & 42329 & $90.7 \%$ & 19718 & $91.5 \%$ & 11884 & $88.6 \%$ \\
\hline Hispanic & 1507 & $1.8 \%$ & 970 & $2.1 \%$ & 320 & $1.5 \%$ & 217 & $1.6 \%$ \\
\hline
\end{tabular}


Table 2 continued

\begin{tabular}{|c|c|c|c|c|c|c|c|c|}
\hline \multirow[t]{3}{*}{ Baseline characteristics } & \multicolumn{8}{|c|}{ Histology } \\
\hline & \multicolumn{2}{|l|}{$\overline{\text { Overall }}$} & \multicolumn{2}{|c|}{ Non-squamous $^{\mathrm{a}}$} & \multicolumn{2}{|c|}{ Squamous } & \multicolumn{2}{|c|}{ Not otherwise specified } \\
\hline & $\begin{array}{l}n \\
81,628\end{array}$ & $\begin{array}{l}\%^{\mathbf{b}} \\
100 \%\end{array}$ & $\begin{array}{l}n \\
46,670\end{array}$ & $\begin{array}{l}\%^{\mathbf{b}} \\
57 \%\end{array}$ & $\begin{array}{l}n \\
21,540\end{array}$ & $\begin{array}{l}\%^{b} \\
26 \%\end{array}$ & $\begin{array}{l}n \\
13,418\end{array}$ & $\begin{array}{l}\%^{b} \\
16 \%\end{array}$ \\
\hline Unknown & 6190 & $7.6 \%$ & 3371 & $7.2 \%$ & 1502 & $7.0 \%$ & 1317 & $9.8 \%$ \\
\hline \multicolumn{9}{|l|}{ Age at diagnosis (in years) } \\
\hline Mean (SD) & \multicolumn{2}{|c|}{$69.1(10.12)$} & \multicolumn{2}{|c|}{$68.5(10.44)$} & \multicolumn{2}{|c|}{$70.3(9.32)$} & \multicolumn{2}{|l|}{$69.4(10.02)$} \\
\hline Median (IQR) & \multicolumn{2}{|c|}{$70(62-77)$} & \multicolumn{2}{|c|}{$69(61-77)$} & \multicolumn{2}{|c|}{$71(64-78)$} & \multicolumn{2}{|l|}{$70(63-77)$} \\
\hline Min-Max & \multicolumn{2}{|l|}{$(18-89)$} & \multicolumn{2}{|l|}{$(18-89)$} & \multicolumn{2}{|l|}{$(23-89)$} & \multicolumn{2}{|l|}{$(21-89)$} \\
\hline$\leq 34$ & 117 & $0.1 \%$ & 89 & $0.2 \%$ & 11 & $0.1 \%$ & 17 & $0.1 \%$ \\
\hline $35-44$ & 835 & $1.0 \%$ & 614 & $1.3 \%$ & 92 & $0.4 \%$ & 129 & $1.0 \%$ \\
\hline $45-54$ & 6161 & $7.5 \%$ & 4004 & $8.6 \%$ & 1151 & $5.3 \%$ & 1006 & $7.5 \%$ \\
\hline $55-64$ & 18797 & $23.0 \%$ & 11475 & $24.6 \%$ & 4423 & $20.5 \%$ & 2899 & $21.6 \%$ \\
\hline $65+$ & 55718 & $68.3 \%$ & 30488 & $65.3 \%$ & 15863 & $73.6 \%$ & 9367 & $69.8 \%$ \\
\hline \multicolumn{9}{|l|}{ ECOG score } \\
\hline \multicolumn{9}{|l|}{ Index \pm 30 days } \\
\hline 0 & 3054 & $28.8 \%$ & 2201 & $31.5 \%$ & 701 & $23.5 \%$ & 152 & $23.9 \%$ \\
\hline 1 & 4372 & $41.2 \%$ & 2866 & $41.0 \%$ & 1261 & $42.3 \%$ & 245 & $38.5 \%$ \\
\hline 2 & 1909 & $18.0 \%$ & 1143 & $16.3 \%$ & 633 & $21.3 \%$ & 133 & $20.9 \%$ \\
\hline 3 & 1010 & $9.5 \%$ & 630 & $9.0 \%$ & 301 & $10.1 \%$ & 79 & $12.4 \%$ \\
\hline 4 & 262 & $2.5 \%$ & 155 & $2.2 \%$ & 80 & $2.7 \%$ & 27 & $4.2 \%$ \\
\hline 5 & 4 & $0.0 \%$ & 2 & $0.0 \%$ & 2 & $0.1 \%$ & 0 & $0.0 \%$ \\
\hline Missing & 71017 & & 39673 & - & 18562 & - & 12782 & - \\
\hline \multicolumn{9}{|l|}{ Stage } \\
\hline \multicolumn{9}{|c|}{ Index through follow-up (localized unknown) \pm 30 days (locally advanced metastatic) } \\
\hline Localized (stage $\leq 3 \mathrm{a})$ & 20425 & $59.4 \%$ & 13103 & $54.0 \%$ & 6807 & $70.6 \%$ & 515 & $100.0 \%$ \\
\hline Locally advanced/metastasis $(\geq 3 \mathrm{~b})$ & 13973 & $40.6 \%$ & 11142 & $46.0 \%$ & 2831 & $29.4 \%$ & 0 & $0.0 \%$ \\
\hline Unknown & 24516 & - & 11395 & - & 6270 & - & 6851 & - \\
\hline Missing & 22714 & - & 11030 & - & 5632 & - & 6052 & - \\
\hline \multicolumn{9}{|l|}{ Cytogenetics } \\
\hline \multicolumn{9}{|l|}{ Any time } \\
\hline EGFR-positive $^{c}$ & 9267 & $38.3 \%$ & 8208 & $44.6 \%$ & 704 & $15.6 \%$ & 355 & $27.2 \%$ \\
\hline EGFR-negative & 5575 & $23.0 \%$ & 4303 & $23.4 \%$ & 988 & $22.0 \%$ & 284 & $21.7 \%$ \\
\hline PD-L1-positive & 1933 & $8.0 \%$ & 1140 & $6.2 \%$ & 730 & $16.2 \%$ & 63 & $4.8 \%$ \\
\hline
\end{tabular}


Table 2 continued

\begin{tabular}{|c|c|c|c|c|c|c|c|c|}
\hline \multirow[t]{3}{*}{ Baseline characteristics } & \multicolumn{8}{|c|}{ Histology } \\
\hline & \multicolumn{2}{|l|}{$\overline{\text { Overall }}$} & \multicolumn{2}{|c|}{ Non-squamous ${ }^{a}$} & \multicolumn{2}{|c|}{ Squamous } & \multicolumn{2}{|c|}{ Not otherwise specified } \\
\hline & $\begin{array}{l}n \\
81,628\end{array}$ & $\begin{array}{l}\%^{\mathbf{b}} \\
100 \%\end{array}$ & $\begin{array}{l}n \\
46,670\end{array}$ & $\begin{array}{l}\%^{\mathbf{b}} \\
57 \%\end{array}$ & $\begin{array}{l}n \\
21,540\end{array}$ & $\begin{array}{l}\%^{b} \\
26 \%\end{array}$ & $\begin{array}{l}n \\
13,418\end{array}$ & $\begin{array}{l}\%^{b} \\
16 \%\end{array}$ \\
\hline PD-L1-negative & 487 & $2.0 \%$ & 354 & $1.9 \%$ & 122 & $2.7 \%$ & 11 & $0.8 \%$ \\
\hline Both & 448 & $1.8 \%$ & 399 & $2.2 \%$ & 38 & $0.8 \%$ & 11 & $0.8 \%$ \\
\hline Other & 6510 & $26.9 \%$ & 4010 & $21.8 \%$ & 1917 & $42.6 \%$ & 583 & $44.6 \%$ \\
\hline Missing & 57408 & - & 28256 & - & 17041 & - & 12111 & - \\
\hline Charlson comorbidity ${ }^{\mathrm{d}}$ & \multicolumn{2}{|c|}{$n=81778$} & \multicolumn{2}{|c|}{$n=38455$} & \multicolumn{2}{|c|}{$n=18004$} & \multicolumn{2}{|l|}{$n=6715$} \\
\hline Mean (SD) & \multicolumn{2}{|c|}{$1.8(2.56)$} & \multicolumn{2}{|c|}{$2(2.74)$} & \multicolumn{2}{|c|}{$1.7(2.34)$} & \multicolumn{2}{|l|}{$1.4(2.22)$} \\
\hline Median & \multicolumn{2}{|l|}{$1(0-3)$} & \multicolumn{2}{|l|}{$1(0-3)$} & \multicolumn{2}{|c|}{$1(0-2)$} & \multicolumn{2}{|l|}{$0(0-2)$} \\
\hline Min-Max & \multicolumn{2}{|l|}{$(0-16)$} & \multicolumn{2}{|l|}{$(0-15)$} & \multicolumn{2}{|l|}{$(0-16)$} & \multicolumn{2}{|l|}{$(0-14)$} \\
\hline
\end{tabular}

ECOG Eastern Cooperative Oncology Group; EGFR epidermal growth factor receptor; $P D-L 1$ programmed death-ligand 1; $I Q R$ interquartile range; $S D$ standard deviation

a Patients with squamous cell carcinoma were compared against patients with non-squamous cell carcinoma only; nonsquamous NSCLC includes adenocarcinoma and large cell lung cancer; patients with unknown histology were excluded from this analysis

${ }^{b}$ Percentages are based on non-missing values in respective cohort

c A patient was EGFR-mutant if identified as EGFR-positive from the SDS data set or had received osimertinib, erlotinib, afatinib, gefitinib or dacomitinib (monotherapy or in combination with chemotherapy drugs) in LOT1. Chemotherapy drugs: Carboplatin, cisplatin, docetaxel, gemcitabine, nab-paclitaxel, paclitaxel, pemetrexed, or vinorelbine

${ }^{\mathrm{d}}$ Comorbidities identified during the 180-day pre-index period

Table 3 Distribution of eligible patients with LOT(s) with their average length of follow-up

\begin{tabular}{lllll}
\hline & $\begin{array}{l}\text { Eligible patients } \\
(\boldsymbol{N}=\mathbf{8 1 , 6 2 8})\end{array}$ & $\begin{array}{l}\text { \% of eligible } \\
\text { patients }\end{array}$ & $\begin{array}{l}\text { \% patients with subsequent } \\
\text { LOT(s) }\end{array}$ & $\begin{array}{l}\text { Median follow-up } \\
\text { (days) }\end{array}$ \\
\hline $\begin{array}{l}\text { Patients with no } \\
\text { treatment }\end{array}$ & 63,949 & 78.3 & - & 146 \\
$\begin{array}{l}\text { Patients with } \geq 1 \\
\text { LOT }\end{array}$ & 17,679 & 21.7 & 40.5 & 401 \\
$\begin{array}{l}\text { Patients with } \geq 2 \\
\text { LOTs }\end{array}$ & 7158 & 8.8 & 42.8 & 566 \\
$\begin{array}{l}\text { Patients with } \geq 3 \\
\text { LOTs }\end{array}$ & 3062 & 3.8 & 43.0 & 742 \\
\hline
\end{tabular}

LOT line of therapy; NSCLC non-small cell lung cancer

${ }^{a}$ Time from index NSCLC diagnosis until the end of continuous follow-up 

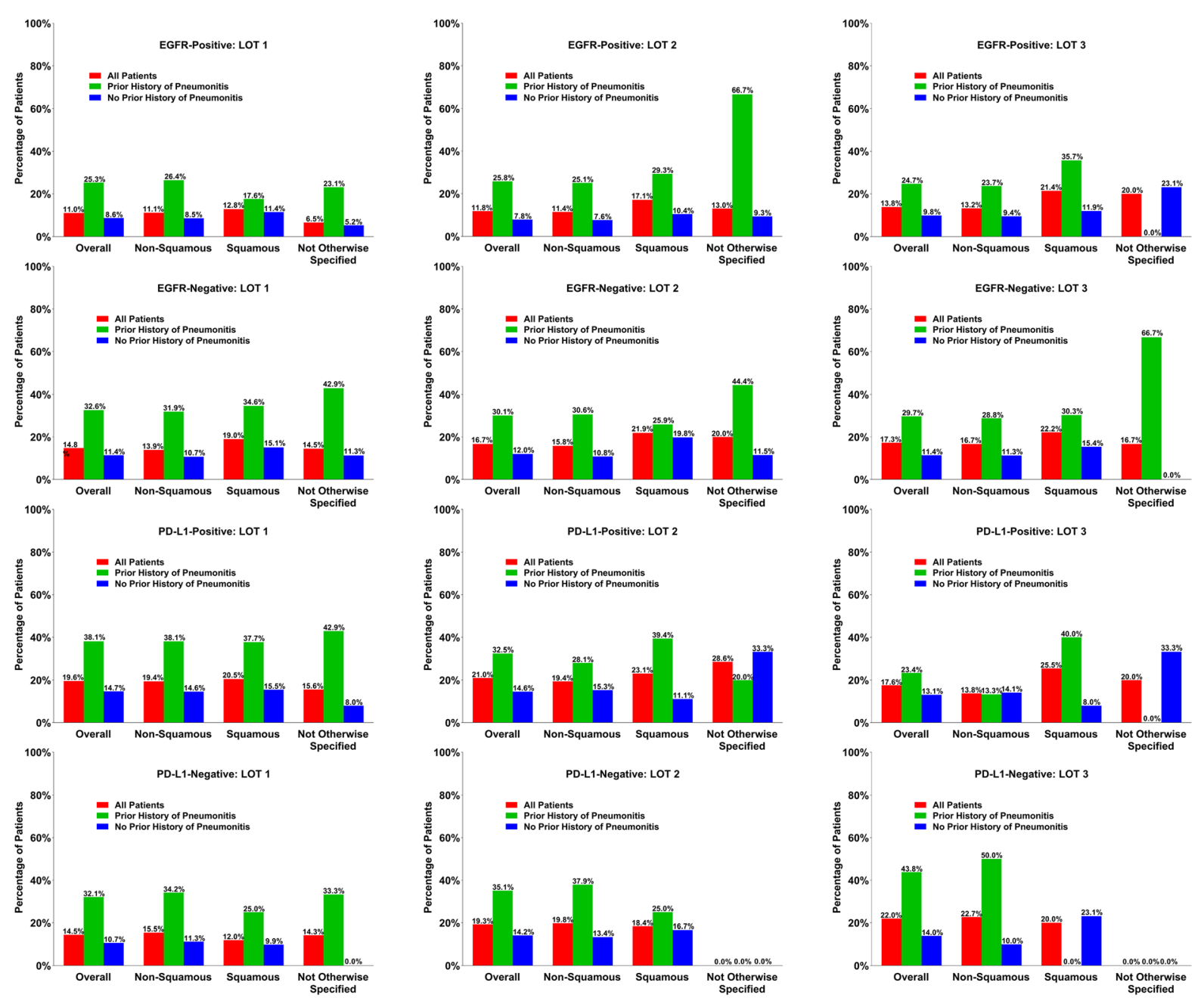

Fig. 2 Cumulative incidence of pneumonitis by biomarker subgroup, LOT, histology, and prior history of pneumonitis. $E G F R$ epidermal growth factor receptor; $L O T$ line of therapy; $P D-L 1$ programmed death-ligand 1

immunomodulatory drug, and history of radiation therapy. Patients treated with other targeted therapies and non-platinum-based chemotherapy showed a lower risk for developing pneumonitis in at least two LOTs.

The multivariable competing risk regression model to identify predictors of pneumonitis for each LOT showed history of pneumonitis to be significant across all three LOTs. Additionally, there were a number of significant predictors across at least two LOTs. Specifically, male gender (LOTs 1-2), EGFR-negative status (LOTs $1-2$ ), and history of radiation therapy (LOTs 1 and 3$)$ were positively associated $(P<0.05)$ with the development of pneumonitis (Table 5). Treatment with other targeted therapy (LOTs
1-2) was negatively associated with developing pneumonitis.

\section{DISCUSSION}

Pneumonitis is a significant and serious $\mathrm{AE}$ associated with drugs used to treat NSCLC. Our study estimated the risk of pneumonitis, among patients diagnosed with NSCLC who received drug interventions, across clinical and treatment characteristics of interest including prior history of pneumonitis, regimen, LOT, histology, and biomarker status. The incidence of pneumonitis in NSCLC has previously been studied mostly in primary and meta-analyses of 


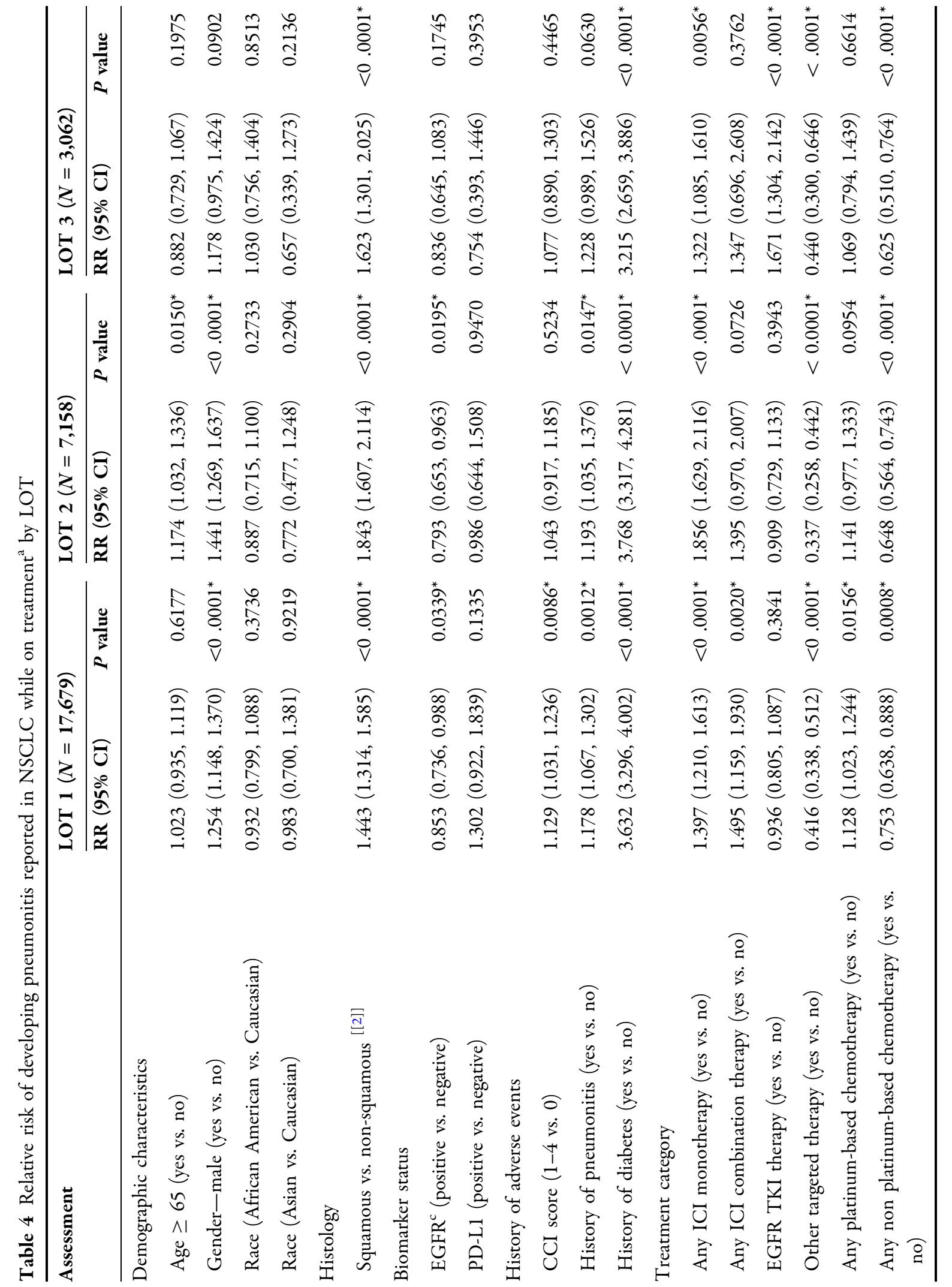




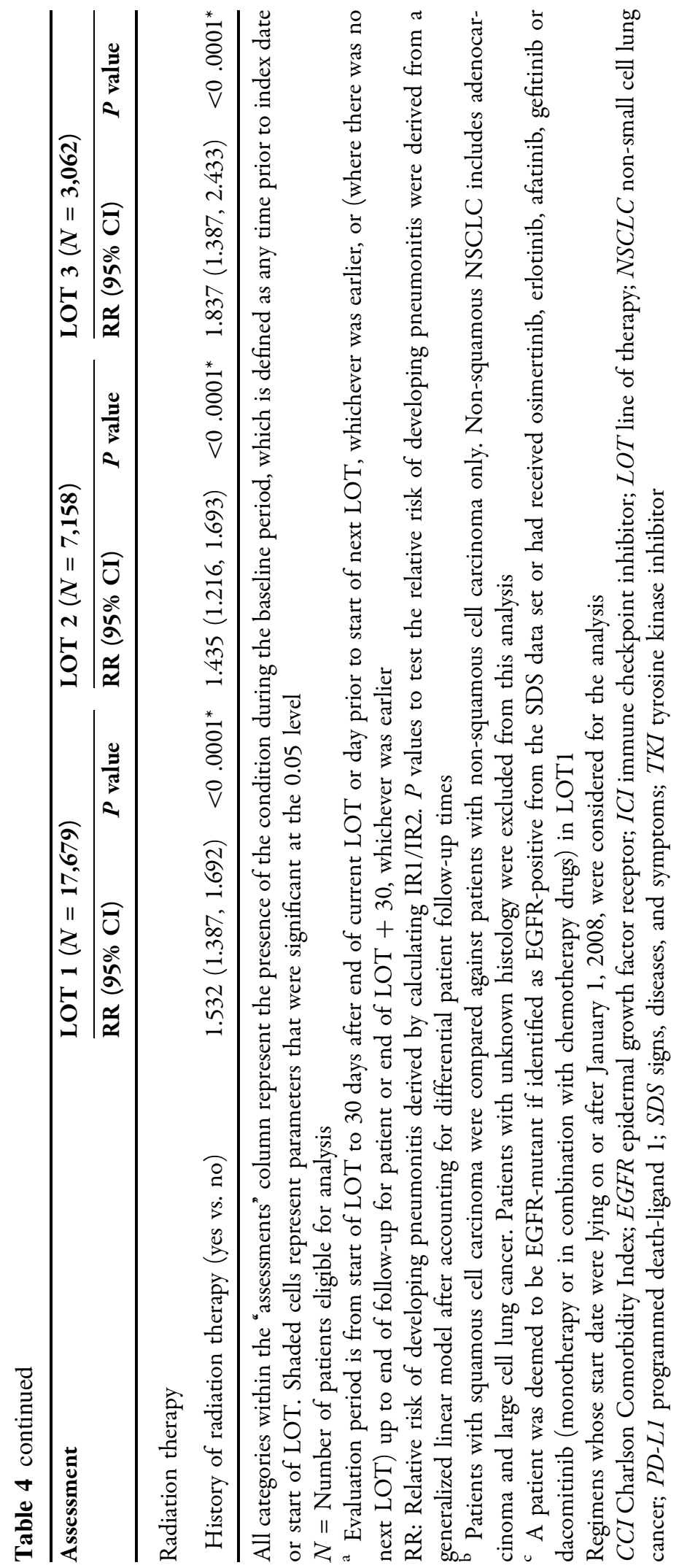


Table 5 Fine and Gray competing risk model for time to pneumonitis while on treatment by LOT $^{\mathrm{a}}$

\begin{tabular}{|c|c|c|c|c|c|c|}
\hline \multirow[t]{2}{*}{ Parameter } & \multicolumn{2}{|l|}{ During LOT 1} & \multicolumn{2}{|l|}{ During LOT 2} & \multicolumn{2}{|l|}{ During LOT 3} \\
\hline & $\begin{array}{l}\text { Hazard ratio } \\
(95 \% \mathrm{CI})\end{array}$ & $P$ value & $\begin{array}{l}\text { Hazard ratio } \\
(95 \% \mathrm{CI})\end{array}$ & $P$ value & $\begin{array}{l}\text { Hazard ratio } \\
(95 \% \mathrm{CI})\end{array}$ & $P$ value \\
\hline \multicolumn{7}{|l|}{ Demographic characteristics } \\
\hline Age $(\geq 65$ vs. $<65)$ & $0.95(0.86-1.05)$ & 0.3388 & $1.08(0.93-1.25)$ & 0.3079 & $0.98(0.79-1.21)$ & 0.8634 \\
\hline $\begin{array}{l}\text { Gender (male vs. } \\
\text { female) }\end{array}$ & $1.15(1.04-1.27)$ & $0.0051^{*}$ & $1.2(1.04-1.39)$ & $0.0143^{*}$ & $1.02(0.81-1.27)$ & 0.8916 \\
\hline $\begin{array}{l}\text { Race (African American } \\
\text { vs. Caucasian) }\end{array}$ & $0.94(0.79-1.11)$ & 0.4602 & $1.01(0.79-1.28)$ & 0.9534 & $1.12(0.8-1.58)$ & 0.5115 \\
\hline $\begin{array}{l}\text { Race (Asian vs. } \\
\text { Caucasian) }\end{array}$ & $1.26(0.88-1.81)$ & 0.2114 & $0.85(0.48-1.53)$ & 0.5931 & $0.98(0.49-1.96)$ & 0.9498 \\
\hline $\begin{array}{l}\text { Race (other/unknown } \\
\text { vs. Caucasian) }\end{array}$ & $1.11(0.87-1.41)$ & 0.4031 & $0.92(0.61-1.38)$ & 0.6853 & $1.09(0.56-2.12)$ & 0.8042 \\
\hline \multicolumn{7}{|l|}{ Histology } \\
\hline $\begin{array}{l}\text { Squamous vs. non- } \\
\text { squamous }\end{array}$ & $1.32(1.18-1.47)$ & $<0.0001^{*}$ & $1.16(0.98-1.38)$ & 0.0901 & $1.28(0.98-1.67)$ & 0.0694 \\
\hline $\begin{array}{l}\text { Unknown vs. non- } \\
\text { squamous }\end{array}$ & $0.85(0.66-1.09)$ & 0.1951 & $1.33(0.94-1.9)$ & 0.1093 & $0.93(0.42-2.03)$ & 0.8538 \\
\hline \multicolumn{7}{|l|}{ Biomarker status } \\
\hline $\begin{array}{l}\mathrm{EGFR}^{\mathrm{c}} \text { (positive vs. } \\
\text { negative) }\end{array}$ & $0.82(0.69-0.98)$ & $0.0273^{*}$ & $0.78(0.62-0.99)$ & $0.0370^{*}$ & $0.86(0.63-1.16)$ & 0.3085 \\
\hline $\begin{array}{l}\text { EGFR (unknown vs. } \\
\text { negative) }\end{array}$ & $0.82(0.71-0.95)$ & $0.0072^{*}$ & $0.83(0.68-1.01)$ & 0.0645 & $0.84(0.62-1.12)$ & 0.2315 \\
\hline $\begin{array}{l}\text { PD-L1 (positive vs. } \\
\text { negative) }\end{array}$ & $1.16(0.8-1.69)$ & 0.4410 & $0.89(0.56-1.39)$ & 0.5984 & $0.71(0.34-1.47)$ & 0.3538 \\
\hline $\begin{array}{l}\text { PD-L1 (unknown vs. } \\
\text { negative) }\end{array}$ & $0.82(0.58-1.16)$ & 0.2643 & $0.69(0.46-1.03)$ & 0.0698 & $0.61(0.32-1.17)$ & 0.1383 \\
\hline \multicolumn{7}{|l|}{ History of adverse events } \\
\hline CCI score ( $1-4$ vs. 0$)$ & $0.98(0.89-1.09)$ & 0.7420 & $0.89(0.77-1.03)$ & 0.1046 & $1.02(0.82-1.27)$ & 0.8500 \\
\hline $\begin{array}{l}\text { History of diabetes (yes } \\
\text { vs. no) }\end{array}$ & $1.02(0.91-1.14)$ & 0.7113 & $1.01(0.86-1.19)$ & 0.9171 & $0.98(0.76-1.25)$ & 0.8445 \\
\hline $\begin{array}{l}\text { History of pneumonitis } \\
\text { (yes vs. no) }\end{array}$ & $2.91(2.6-3.25)$ & $<0.0001^{*}$ & $2.9(2.51-3.36)$ & $<0.0001^{*}$ & $2.91(2.35-3.6)$ & $<0.0001^{*}$ \\
\hline Treatment category & & & & & & \\
\hline $\begin{array}{l}\text { Any ICI monotherapy } \\
\text { (yes vs. no) }\end{array}$ & $1.64(0.89-3.02)$ & 0.1104 & $1.92(1.04-3.56)$ & $0.0375^{*}$ & $1.45(0.68-3.09)$ & 0.3302 \\
\hline
\end{tabular}


Table 5 continued

\begin{tabular}{|c|c|c|c|c|c|c|}
\hline \multirow[t]{2}{*}{ Parameter } & \multicolumn{2}{|l|}{ During LOT 1} & \multicolumn{2}{|l|}{ During LOT 2} & \multicolumn{2}{|l|}{ During LOT 3} \\
\hline & $\begin{array}{l}\text { Hazard ratio } \\
(95 \% \mathrm{CI})\end{array}$ & $P$ value & $\begin{array}{l}\text { Hazard ratio } \\
(95 \% \mathrm{CI})\end{array}$ & $P$ value & $\begin{array}{l}\text { Hazard ratio } \\
(95 \% \mathrm{CI})\end{array}$ & $P$ value \\
\hline $\begin{array}{l}\text { Any ICI combination } \\
\text { therapy (yes vs. no) }\end{array}$ & $1.06(0.78-1.44)$ & 0.6984 & $1.58(1.04-2.4)$ & $0.0305^{*}$ & $1.5(0.77-2.95)$ & 0.2370 \\
\hline $\begin{array}{l}\text { EGFR TKI therapy (yes } \\
\text { vs. no) }\end{array}$ & $0.95(0.52-1.76)$ & 0.8729 & $0.94(0.49-1.79)$ & 0.8443 & $1.04(0.49-2.22)$ & 0.9149 \\
\hline $\begin{array}{l}\text { Other targeted therapy } \\
\text { (yes vs. no) }\end{array}$ & $0.55(0.43-0.71)$ & $<.0001^{*}$ & $0.58(0.41-0.83)$ & $0.0027^{*}$ & $0.73(0.45-1.21)$ & 0.2247 \\
\hline $\begin{array}{l}\text { Any platinum-based } \\
\text { chemotherapy (yes vs. } \\
\text { no) }\end{array}$ & $0.92(0.52-1.66)$ & 0.7909 & $0.98(0.53-1.79)$ & 0.9395 & $0.76(0.36-1.63)$ & 0.4856 \\
\hline $\begin{array}{l}\text { Any non-platinum- } \\
\text { based chemotherapy } \\
\text { (yes vs. no) }\end{array}$ & $0.9(0.49-1.65)$ & 0.7342 & $1.12(0.62-2.05)$ & 0.7069 & $0.73(0.36-1.51)$ & 0.3957 \\
\hline \multicolumn{7}{|l|}{ Radiation therapy } \\
\hline $\begin{array}{l}\text { History of radiation } \\
\text { therapy (yes vs. no) }\end{array}$ & $1.33(1.19-1.49)$ & $<0.0001^{*}$ & $1.14(0.95-1.38)$ & 0.1647 & $1.46(1.07-2)$ & $0.0181^{*}$ \\
\hline
\end{tabular}

CCI Charlson Comorbidity Index; EGFR epidermal growth factor receptor; ICI immune checkpoint inhibitor; LOT line of therapy; $P D-L 1$ programmed death-ligand 1; TKI, tyrosine kinase inhibitor

a Regimens whose start dates were on or after January 1, 2008, were considered for the analysis. Assessment period is from start of LOT to 30 days after end of current LOT or day prior to start of next LOT, whichever is earlier, or (where no next LOT) up to end of follow-up for patient or end of LOT +30 , whichever is earlier. Shaded cells represent parameters that were significant at the 0.05 level

b Patients with squamous cell carcinoma were compared against patients with non-squamous cell carcinoma only. Nonsquamous NSCLC includes adenocarcinoma and large cell lung cancer. Patients with unknown histology were excluded from this analysis

clinical trials $[6,[7,11]$, and in some retrospective chart reviews from select hospitals $(8,9)$. This has resulted in a wide range of estimates from $3-5 \%$ in the clinical trial setting $[7,31]$ to 19-21\% from additional trials or hospital data $[14,32]$. This discrepancy may be explained in part by the increased awareness of this $\mathrm{AE}$ in recent years and partly to enhanced pharmacovigilance following the administration of targeted agents [14].

In our analysis of EHR data from hospital clinics across the country, the cumulative incidence of pneumonitis among NSCLC patients was estimated to be $19.0 \%$ during any LOT, and
$33.7 \%$ among those with a prior history of pneumonitis and $17.0 \%$ for those without a previous history of pneumonitis. Competing risk regression revealed various factors to be positively associated with the development of pneumonitis over multiple LOTs. Predictors of increased pneumonitis risk included a previous history of pneumonitis, male gender, history of radiation therapy, and EGFR-negative status.

To our knowledge, only two other studies have examined rates of pneumonitis in large real-world data sets. The first study used OptumLabs administrative claims data and examined frequencies of all immune-related 
adverse events (irAEs) in NSCLC patients receiving PD-L1 inhibitors [19]. Pneumonitis was reported in $2.5 \%$ of 3164 patients within a month of receipt of a PD-L1 inhibitor, increasing to $14.3 \%$ after 9 months. The second study, a retrospective analysis of the Symphony Health administrative claims data, estimated incidence, and timing of radiation-induced pneumonitis following chemoradiotherapy in patients with stage III NSCLC [22]. The cumulative incidence of treatment-related pneumonitis was reported to be $12.4 \%$, with the annual incidence ranging from $5.5 \%$ to $18.1 \%$. The higher rates in our study are perhaps explained by the inclusion of more stage IV patients and the effect of more patients having been treated with PD-L1 inhibitors.

Limitations associated with using real-world data need to be recognized. The data for this study were not recorded for research purposes; as such there may be coding errors that could affect the treatment patterns and predictive factors associated with pneumonitis. While this is a large multi-source database, it may not be nationally representative of all NSCLC patients. A final limitation is with the use of NLP for identifying patients of non-small cell cancer histology and partly for diagnosis of pneumonitis. We rely on the data vendor's NLP algorithm for this and cannot know how well the NLP extracts the information from the physician notes.

Future research building on this study could include using another US-based EHR data source that is focused on community and academic based hematology-oncology clinics or using a non-US real-world data source.

Pneumonitis remains a significant risk in patients diagnosed with NSCLC. This study identified independent factors that may predispose individuals to pneumonitis risk such as previous history of pneumonitis, male gender, EGFR-negative status, ICI therapy, other targeted therapies, or history of radiation. Awareness and monitoring of these factors may help mitigate the risk of pneumonitis for these patients.

\section{CONCLUSION}

Pneumonitis is a significant side effect of medicines developed to treat NSCLC. Recognition of this fact and awareness of the different factors predisposing patients to its development will help physicians proactively tailor treatment regimens to reduce the likelihood of its onset. Patients may consequently be able to better adhere to treatment regimens, leading to positive clinical outcomes and improved quality of life.

\section{ACKNOWLEDGEMENTS}

Funding. This study was funded by Abbvie, Inc., North Chicago, Illinois, USA. The journal's Rapid Service fee was funded by AbbVie.

Medical Writing Assistance. Assistance with the preparation of this manuscript was provided by Prasad Kulkarni, PhD, CMPP, of Asclepius Medical Communications LLC, Ridgewood, New Jersey. Funding for this assistance was provided by SmartAnalyst Inc.

Authorship. All named authors meet the International Committee of Medical Journal Editors (ICMJE) criteria for authorship for this article, take responsibility for the integrity of the work as a whole, and have given their approval for this version to be published.

Authorship contributions. Jerzy Tyczynski, Ravi Potluri, Debasish Mazumder, and Alexander Liede contributed to the study conception and design. Jerzy Tyczynski, Ravi Potluri, Ryan Kilpatrick, and Alexander Liede helped in acquiring the data. Ravi Potluri, Debasish Mazumder, and Anirban Ghosh analyzed the data. Jerzy Tyczynski, Ravi Potluri, Debasish Mazumder, Ryan Kilpatrick, and Alexander Liede were involved in interpreting the data. Jerzy Tyczynski, Ravi Potluri, Debasish Mazumder, and Alexander Liede all contributed to drafting the manuscript. All authors were involved in revisions and all authors read and approved the final manuscript. 
Compliance with Ethics Guidelines. The anonymized patient information used in this retrospective observational study does not include any identifiable information as defined by the Health Insurance Portability and Accountability Act (HIPAA) of 1996, and an institutional review board (IRB) approval or waiver is therefore not required. The authors licensed the data from Optum and had permission to use it for this research.

Disclosures. Jerzy Tyczynski, Ryan Kilpatrick, and Alexander Liede are employees of AbbVie and own stock. Ravi Potluri, Debasish Mazumder, and Anirban Gosh are employed by SmartAnalyst and received funding from AbbVie to conduct the study.

Data Availability. The data sets generated and/or analyzed during the current study are not publicly available due to the proprietary nature of the database from which they were derived and used under license for the current study.

Open Access. This article is licensed under a Creative Commons Attribution-NonCommercial 4.0 International License, which permits any non-commercial use, sharing, adaptation, distribution and reproduction in any medium or format, as long as you give appropriate credit to the original author(s) and the source, provide a link to the Creative Commons licence, and indicate if changes were made. The images or other third party material in this article are included in the article's Creative Commons licence, unless indicated otherwise in a credit line to the material. If material is not included in the article's Creative Commons licence and your intended use is not permitted by statutory regulation or exceeds the permitted use, you will need to obtain permission directly from the copyright holder. To view a copy of this licence, visit http://creativecommons.org/licenses/by$\mathrm{nc} / 4.0 /$.

\section{REFERENCES}

1. Siegel RL, Miller KD, Fuchs HE, Jemal A. Cancer statistics, 2021. Ca Cancer J Clin. 2021;71(1):7-33.

2. Siegel RL, Miller KD, Fuchs HE, Jemal A. Cancer statistics, 2021. Ca Cancer J Clin. 2020;70(1):7-30.

3. Salehi-Rad R, Li R, Paul MK, Dubinett SM, Liu B. The biology of lung cancer: development of more effective methods for prevention diagnosis and treatment. Clin Chest Med. 2020;41(1):25-38.

4. Yuan M, Huang LL, Chen JH, Wu J, Xu Q. The emerging treatment landscape of targeted therapy in non-small-cell lung cancer. Signal Transduct Target Ther. 2019;4:61.

5. Chen R, Manochakian R, James L, Azzouqa AG, Shi $\mathrm{H}$, Zhang $\mathrm{Y}$, et al. Emerging therapeutic agents for advanced non-small cell lung cancer. J Hematol Oncol. 2020;13(1):58.

6. Nishino M, Giobbie-Hurder A, Hatabu H, Ramaiya $\mathrm{NH}$, Hodi FS. Incidence of programmed cell death 1 inhibitor-related pneumonitis in patients with advanced cancer: a systematic review and metaanalysis. Jama Oncol. 2016;2(12):1607-16.

7. Khunger M, Rakshit S, Pasupuleti V, Hernandez AV, Mazzone P, Stevenson J, et al. Incidence of pneumonitis with use of programmed death 1 and programmed death-ligand 1 inhibitors in non-small cell lung cancer: a systematic review and metaanalysis of trials. Chest. 2017;152(2):271-81.

8. Naidoo J, Wang X, Woo KM, Iyriboz T, Halpenny D, Cunningham J, et al. Pneumonitis in patients treated with anti-programmed death-1/programmed death ligand therapy. J Clin Oncol. 2017;35(7):709-17.

9. Cho JY, Kim J, Lee JS, Kim YJ, Kim SH, Lee YJ, et al. Characteristics, incidence, and risk factors of immune checkpoint inhibitor-related pneumonitis in patients with non-small cell lung cancer. Lung Cancer. 2018;125:150-6.

10. Oshima Y, Tanimoto T, Yuji K, Tojo A. EGFR-TKIassociated interstitial pneumonitis in nivolumabtreated patients with non-small cell lung cancer. Jama Oncol. 2018;4(8):1112-5.

11. Suh $\mathrm{CH}$, Park HS, Kim KW, Pyo J, Hatabu H, Nishino M. Pneumonitis in advanced non-small-cell lung cancer patients treated with EGFR tyrosine kinase inhibitor: meta-analysis of 153 Cohorts with 15,713 patients: meta-analysis of incidence and risk factors of EGFR-TKI pneumonitis in Nsclc. Lung Cancer. 2018;123:60-9. 
12. Kishikawa T, Kasai T, Okada M, Nakachi I, Soda S, Arai R, et al. Osimertinib, a third-generation EGFR tyrosine kinase inhibitor: a retrospective multicenter study of its real-world efficacy and safety in advanced/recurrent non-small cell lung carcinoma. Thorac Cancer. 2020;11(4):935-42.

13. Hwang HJ, Kim MY, Choi CM, Lee JC. Anaplastic lymphoma kinase inhibitor related pneumonitis in patients with non-small cell lung cancer: clinical and radiologic characteristics and risk factors. Medicine (Baltimore). 2019;98(48):E18131.

14. Suresh K, Voong KR, Shankar B, Forde PM, Ettinger DS, Marrone KA, et al. Pneumonitis in non-small cell lung cancer patients receiving immune checkpoint immunotherapy: incidence and risk factors. J Thorac Oncol. 2018;13(12):1930-9.

15. Naidoo J, Page DB, Li BT, Connell LC, Schindler K, Lacouture ME, et al. Toxicities Of the Anti-Pd-1 and Anti-Pd-L1 immune checkpoint antibodies. Ann Oncol. 2015;26(12):2375-91.

16. Postow MA. Managing immune checkpoint-blocking antibody side effects. Am Soc Clin Oncol Educ Book. 2015;15:76-83.

17. Topalian SL, Hodi FS, Brahmer JR, Gettinger SN, Smith DC, McDermott DF, et al. Safety, activity, and immune correlates of anti-Pd-1 antibody in cancer. N Engl J Med. 2012;366(26):2443-54.

18. Brahmer JR, Lacchetti C, Schnaider BJ, Atkins MB, Brassil KJ, Caterino JM, et al. Management of immune-related adverse events in patients treated with immune checkpoint inhibitor therapy: American Society of Clinical Oncology clinical practice guideline. J Clin Oncol. 2018;36(17):1714-68.

19. Cathcart-Rake EJ, Sangaralingham LR, Henk HJ, Shah ND, Riaz IB, Mansfield AS. A population-based study of immunotherapy-related toxicities in lung cancer. Clin Lung Cancer. 2020;S1525-7304(20): 30102-9.

20. Khozin S, Miksad RA, Adami J, Boyd M, Brown NR, Gossai A, et al. Real-world progression, treatment, and survival outcomes during rapid adoption of immunotherapy for advanced non-small cell lung cancer. Cancer. 2019;125(22):4019-32.

21. Liede A, Hernandez RK, Wade SW, Bo R, Nussbaum $\mathrm{NC}$, Ahern E, et al. An observational study of concomitant immunotherapies and denosumab in patients with advanced melanoma or lung cancer. Oncoimmunology. 2018;7(12):E1480301.

22. Ryan KJ, Nero D, Feinberg BA, Lee $\mathrm{CH}$, Pimentel R, Gajra A, et al. Real-world incidence and cost of pneumonitis post-chemoradiotherapy for stage III non-small-cell lung cancer. Future Oncol. 2020;16(1):4303-13.

23. Stewart M, Norden AD, Dreyer N, Henk HJ, Abernethy AP, Chrischilles E, et al. An exploratory analysis of real-world end points for assessing outcomes among immunotherapy-treated patients with advanced non-small-cell lung cancer. Jco Clin Cancer Inform. 2019;3:1-15.

24. Griffith Sd, Tucker M, Bowser B, Calkins G, Chang CJ, Guardino E, et al. Generating real-world tumor burden endpoints from electronic health record data: comparison of recist, radiology-anchored, and clinician-anchored approaches for abstracting realworld progression in non-small cell lung cancer. Adv Ther. 2019;36(8):2122-36.

25. Griffith SD, Miksad RA, Calkins G, You P, Lipitz NG, Bourla $\mathrm{AB}$, et al. Characterizing the feasibility and performance of real-world tumor progression end points and their association with overall survival in a large advanced non-small-cell lung cancer data set. JCO Clin Cancer Inform. 2019;3:1-13.

26. Wallace PJ, Shah ND, Dennen T, Bleicher PA, Crown WH. Optum labs: building a novel node in the learning health care system. Health Aff (Millwood). 2014;33(7):1187-94.

27. Pettus JH, Zhou FL, Shepherd L, Mercaldi K, Preblick R, Hunt PR, et al. Differences between patients with type 1 diabetes with optimal and suboptimal glycaemic control: a real-world study of more than 30000 patients in a US electronic health record database. Diabetes Obes Metab. 2020;22(4):622-30.

28. Edemekong PF, Annamaraju P, Haydel MJ. Health Insurance Portability And Accountability Act

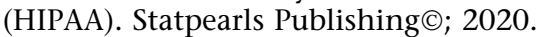

29. Broome CM, Cunningham JM, Mullins M, Jiang X, Bylsma LC, Fryzek JP, et al. Increased risk of thrombotic events in cold agglutinin disease: a 10-year retrospective analysis. Res Pract Throm Haem. 2020;4(4):628-35.

30. Fine JP, Gray RJ. A proportional hazards model for the subdistribution of a competing risk. J Am Stat Assoc. 1999;94(446):496-509.

31. De Velasco G, Je Y, Bossé D, Awad MM, Ott PA, Moreira RB, et al. Comprehensive meta-analysis of key immune-related adverse events from CTLA-4 and PD-1/PD-L1 inhibitors in cancer patients. Cancer Immunol Res. 2017;5(4):312.

32. Voong KR, Hazell S, Hu C, Hayman J, Hales R, Marrone K, et al. MA 09.08 receipt of chest radiation and immune-related pneumonitis in patients with NSCLC treated with anti-PD-1/PD-L1. J Thoracic Oncol. 2017;12(11):S1837. 